\title{
Watershed-scale assessment of arsenic and metal contamination in the surface soils surrounding Miyun Reservoir, Beijing, China
}

\author{
Wei Luo ${ }^{a}$, Yonglong $\mathrm{Lu}^{\mathrm{a}}{ }^{\text {,*}}$, Yan Zhang ${ }^{\mathrm{a}}$, Wenyou $\mathrm{Fu}^{\mathrm{a}}$, Bin Wang ${ }^{\mathrm{a}}$, Wentao Jiao ${ }^{\mathrm{a}}$, Guang Wang ${ }^{\mathrm{a}}$, \\ Xiaojuan Tong ${ }^{\mathrm{b}}$, John P. Giesy ${ }^{\mathrm{c}, \mathrm{d}}$ \\ a State Key Lab of Urban and Regional Ecology, Research Center for Eco-Environmental Sciences, Chinese Academy of Sciences, Beijing 100085, China \\ ${ }^{\mathrm{b}}$ College of Forestry, Beijing Forestry University, Beijing 100083, China \\ ${ }^{\mathrm{c}}$ Department of Veterinary Biomedical Sciences and Toxicology Centre, University of Saskatchewan, Saskatoon, Saskatchewan, Canada \\ ${ }^{\mathrm{d}}$ Zoology Dept., Center for Integrative Toxicology, Michigan State University, East Lansing, MI 48824, USA
}

\section{A R T I C L E I N F O}

\section{Article history:}

Received 28 September 2009

Received in revised form

17 June 2010

Accepted 18 July 2010

Available online 10 August 2010

\section{Keywords:}

Multivariate statistical analysis

Geostatistical analysis

Ordinary kriging

Disjunctive kriging

Contamination risk assessment

\begin{abstract}
A B S T R A C T
Concentrations of As and selected metals were determined in surface soils of the Miyun Reservoir watershed of Beijing, China. The degree to which concentrations of As and metals exceeded the corresponding background concentration of soils was: $\mathrm{Cr}>\mathrm{Cu}>\mathrm{Zn}>\mathrm{As}>\mathrm{Ni}$ with no apparent anthropogenic contamination with $\mathrm{Cd}$ and $\mathrm{Pb}$. Based on the results of a combination of multivariate statistics and geostatistical analysis, greater concentrations of $\mathrm{Cr}$ and $\mathrm{Ni}$ in soils were determined to be primarily from iron ore mining near where the Chaohe River enters the northeast portion of the reservoir. Agricultural activities were responsible for the observed elevated concentrations of $\mathrm{Cu}$ and $\mathrm{Zn}$ in soils. Relatively great concentrations of As were found in soils near the upstream regions of the Baihe River in Chicheng County where small gold mining activities have taken place. The greatest potential for adverse effects of $\mathrm{Cr}$ and $\mathrm{Cu}$ occurred along the eastern shore of Miyun Reservoir.
\end{abstract}

(ㄷ) 2010 Elsevier Ltd. All rights reserved.

\section{Introduction}

Miyun Reservoir is the main source of drinking water for Beijing, China. Miyun Reservoir has been influenced over the past 30 years, particularly during the 1980s, by agricultural and industrial development in the northern portions of the Beijing region. In particular runoff from non-point sources, direct dumping of wastes, mineral exploitation, and pollutants carried by rivers have resulted in elevated concentrations of As and metals in soils and surface waters.

Soils can be contaminated by a number of pollutants from industrial, agricultural, and transportation activities. The increasing amounts of As and metals in soils can reach surface and ground waters through runoff and leaching. Therefore, accumulation of As and metals in soils can affect the quality of water which can potentially affect terrestrial and aquatic communities and can directly and indirectly affect the quality and quantity of drinking water (Bonten et al., 2006; Schipper et al., 2008). Contaminated

\footnotetext{
* Corresponding author. Tel.: +86 10 62849466; fax: +8610 62918177

E-mail address: yllu@rcees.ac.cn (Y. Lu).
}

soils can affect human health through the water supply and aquatic and terrestrial food chains (Zhang et al., 2007).

Evaluation of the status and trends in concentrations, distribution, and sources of As and metals measured in soils is challenging but necessary to provide information required for comprehensive environmental risk assessments. Multivariate statistical techniques such as principal component analysis (PCA) and cluster analysis (CA) and geostatistical analysis have been widely used as to identify probable sources of As and metals and attribute sources natural or human-caused contributions, and to describe spatial distribution of pollutants (Tao, 1995; Facchinelli et al., 2001; Li et al., 2004; Luo et al., 2007; Rodríguez Lado et al., 2008). Combining statistical and spatial analysis tools has been shown to be particularly useful in risk assessment (Carlon et al., 2001).

Earlier work has examined As and metals in soils upstream of Miyun Reservoir. It has been reported that some soils have been contaminated by As and metals including $\mathrm{Cr}, \mathrm{Cu}, \mathrm{Ni}$, and $\mathrm{Hg}$. Concentrations of As and metals in soils have been attributed primarily to mining activities, including iron, chromite and gold, upstream of Miyun Reservoir (Gao and Liao, 2007). In recent years, concentrations of As and metals in water upstream of the reservoir have increased gradually (Liu et al., 2005). Some elements such as $\mathrm{Cu}, \mathrm{Cr}, \mathrm{Ni}, \mathrm{Cd}, \mathrm{As}, \mathrm{Pb}$ and $\mathrm{Hg}$ have been detected in drinking water 
and the sediment of Miyun Reservoir (Ge et al., 2003; Liu et al., 2005; Zhuang et al., 2005). As and metals in water and sediment of the reservoir present potential risks for the aquatic ecosystem and human health (Ge et al., 2003). Historically, metal contamination, sources and risk in soils around Miyun Reservoir and its watershed had not been systematically assessed. Thus, it has been difficult to identify potential sources of As and metals or determine the risk posed to water ecosystems at the watershed scale or to formulate effective management plans and policies to reduce metal inputs to soil and sources of water for drinking.

The aims of the study were to: (1) determine average concentrations of As and selected metals $(\mathrm{Cr}, \mathrm{Cu}, \mathrm{Cd}, \mathrm{Pb}, \mathrm{Zn}$ and $\mathrm{Ni}$ ) in soils near sources of drinking water for Beijing; (2) define their natural or anthropogenic sources using multivariate statistical and geostatistical analysis; (3) use spatial analysis method in GIS to produce geochemical maps of As and metals and identify possible hot-spots of elevated concentrations of As and metals; and (4) assess the risks from As and metals in soils around drinking water source sites.

\section{Materials and methods}

\subsection{Site description}

Miyun Reservoir, situated in the mountainous area of Miyun County of the Beijing District, is the largest reservoir in north China, with a surface area of $188 \mathrm{~km}^{2}$ and watershed area of $15,788 \mathrm{~km}^{2}$. Constructed in 1960, it is now the only drinking water source for Beijing City. More than ten million people inhabiting the city of Beijing depend on Miyun Reservoir for drinking water. The upper basin of the reservoir, covering an area of 1,535,400 ha, includes two counties in Beijing and six counties in Hebei Province. The main sources of water to Miyun Reservoir are the Chaohe and Baihe Rivers (Fig. 1). The average annual runoff of the Baihe River $\left(7.22 \times 10^{9} \mathrm{~m}^{3}\right)$ is greater than that of the Chaohe River $\left(4.05 \times 10^{9} \mathrm{~m}^{3}\right)$ (Wang et al., 2003). The main land uses are forestry and farming which represent $50 \%$ and $15 \%$ of the total land area, respectively. The vicinity to the north of Miyun Reservoir is mountains and forests with a sparse population. To the east of Miyun Reservoir are lower hills with dense populations. Therefore, human activities are focused to the east of the reservoir. The soil types around Miyun Reservoir are mainly argosols, cambosols and aridosols, namely, luvisols, alisols, cambisols, calcisols and gypsisols respectively, based on World Reference Base for Soil Resources (Gong et al., 2002). Upstream of Miyun Reservoir has thin soil and little vegetation cover, which results in great soil erosion (Liu et al., 2005). Therefore, the Miyun Reservoir watershed was considered a priority area for soil conservation. To protect drinking water, agricultural and industrial activities in this area are strictly limited and regulated. However, contamination from the watershed of Miyun Reservoir is still severe. The contamination mainly comes from non-point sources such as fertilizer (especially manure), pesticides and some point sources, such as mining exploration, especially in the delta of the Chaohe River (Gao and Liao, 2007).

\subsection{Soil sampling}

A total of 95 sampling blocks $(100 \mathrm{~m} \times 100 \mathrm{~m})$ were identified from an area of approximately $250 \times 200 \mathrm{~km}^{2}$ on an irregular grid fitted to the local conditions (including soil types, land use, terrain and landscape), based on a nested sampling design. To evaluate concentrations of As and metals in soils and the potential for adverse effects to the reservoir, sample locations were most densely collected near the reservoir and its tributaries where the most human-impacted areas were also located. Samples were spaced farther apart with increasing distance from Miyun Reservoir and its tributaries where there was less human activity and lesser variability in concentrations of As and metals and the presence of mountains and narrow valleys (Fig. 1). Throughout the survey a global positioning system (GPS) was used to determine sampling positions. At each sampling block, 5 subsamples $(0-20 \mathrm{~cm}$ depth) were taken from the 4 vertexes and the center of a square block and mixed thoroughly to select $1 \mathrm{~kg}$ soil as the representative sample of the block. This procedure resulted in 95 composite soil samples from a total of 475 individual soil sub-samples. The soil sampling was performed, based on The Technical Specification for Soil Environmental Monitoring (State Environmental Protection Administration of China, 2004).

\subsection{Chemical analysis}

Soil samples were air-dried, crushed in an agate mortar, passed through a nylon sieve of 100 mesh, and digested with $\mathrm{HNO}_{3}$ and $\mathrm{H}_{2} \mathrm{O}_{2}$ using Method 3050B (USEPA, 1996). All materials used during analytical determinations were kept in Teflon or other metal-free containers. Total concentrations of $\mathrm{Cd}, \mathrm{Cr}, \mathrm{Zn}, \mathrm{As}, \mathrm{Cu}, \mathrm{Ni}$ and $\mathrm{Pb}$ were measured by inductively coupled plasma mass spectrometry (ICPMS). To check the quality of preparation and analysis, replicate determinations were performed on approximately $25 \%$ of samples. The method detection limit (MDL), which is defined as the minimum concentration of substance that can be measured and reported with 99\% confidence, was determined using EPA 40CFR Part 136, Appendix B. Standard reference materials, GSS-1 soils, obtained from the Center of National Standard Reference Material of China were analyzed as part of the quality assurance and quality control $(\mathrm{QA} / \mathrm{QC})$ procedures. Satisfactory recoveries were obtained for $\mathrm{Cu}(91-97 \%), \mathrm{Ni}$ (99-105\%), Pb (95-104\%), Cd (96-101\%), As (98-103\%) and Zn (92-104\%).

\subsection{Statistical analysis and risk assessment}

Distributions and associations of concentrations of As and metals were investigated by a combination of univariate and multivariate parametric statistics. In multivariate statistics and linear geostatistics, a normal distribution for the variables under study is desirable (Webster and Oliver, 2001). Concentrations of As and metals were $\log _{10}$-transformed to make the data less skewed and more closely approximate a normal distribution. Normality of the $\log _{10}$-transformed concentrations was assessed using the Kolmogorov-Smirnov (K-S) test. Correlation analysis and principal component analysis (PCA) were used to evaluate concentrations of As and metals. Correlations were evaluated using the bivariation method, with two-tailed significance and Pearson correlation coefficients. In the PCA, Varimax with Kaiser normalization was used as the rotation method in the analysis (García et al., 2004). As suggested by the Kaiser criterion (Kaiser, 1960) all principal factors with eigenvalues $>1.0$ extracted from the variables were retained. Statistical analysis were performed using SPSS $13.0^{\circledR}$ statistical software.

Geostatistical methods were used to calculate the semivariogram (Eq. (1)):

$r(h)=\left(\frac{1}{2 N(h)}\right) \sum_{i=1}^{N(h)}\left[Z\left(x_{i}\right)-Z\left(x_{i}+h\right)\right]^{2}$

where: $Z\left(x_{i}\right)$ represents the measured value for concentrations of As and metals in soil at locations of $x_{i}$, and $r(h)$ is the semivariogram for a lag distance $h$ between observations $Z\left(x_{i}\right)$ and $Z\left(x_{i}+h\right)$, and $N$ $(h)$ is the number of data pairs separated by $h$. Semivariograms $r(h)$ for the concentrations of As and metals in soils were calculated and 


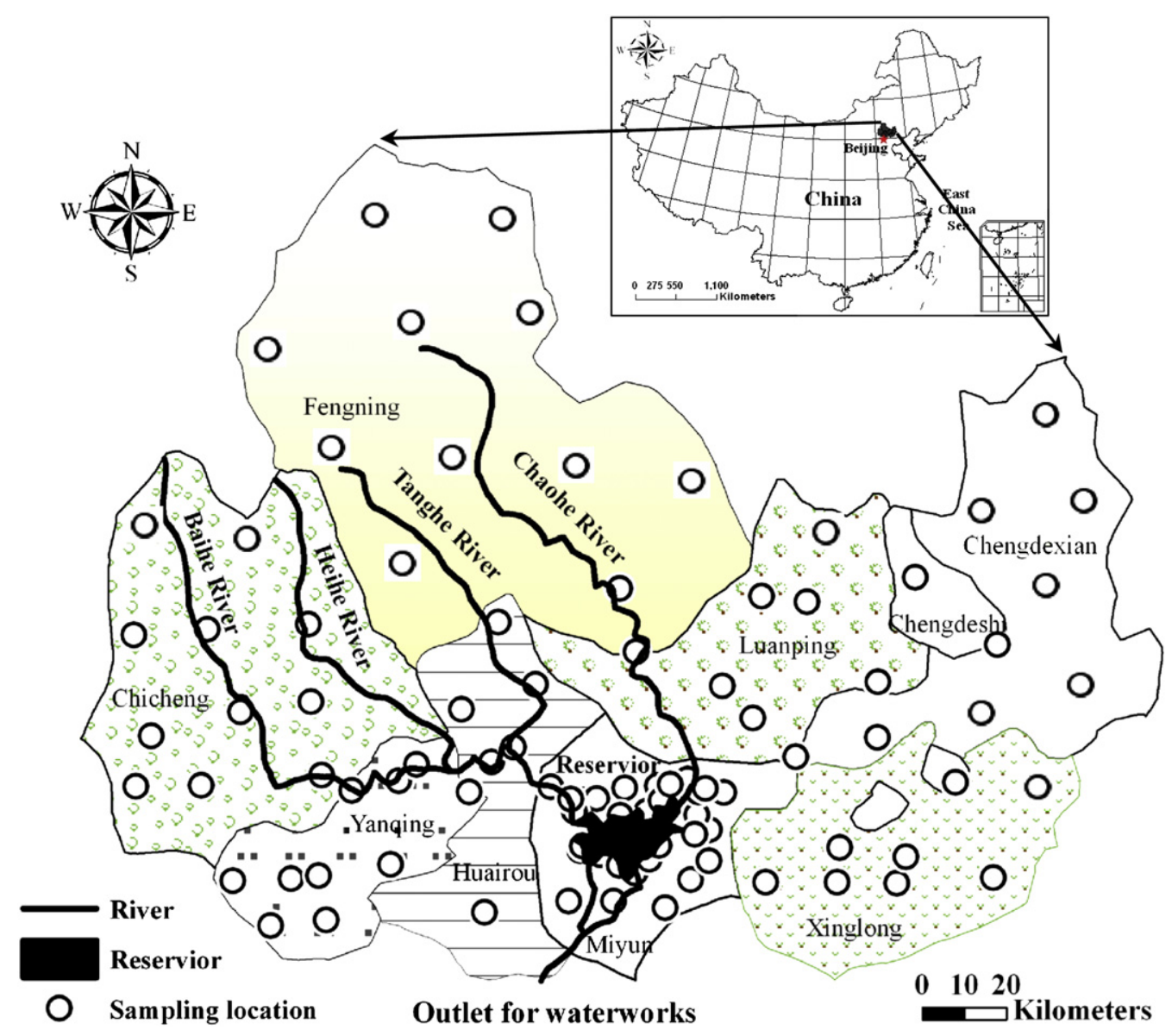

Fig. 1. Map of soil sampling sites around Miyun Reservoir.

the scatter plot of $r(h)$ vs. $h$ was generated. Then different theoretical semivariance models (e.g., spherical, exponential, Gaussian, linear, and linear to sill) were used to fit the experimental semivariogram. The appropriate theory model and the parameters for kriging interpolation (e.g., range, nugget $\left(C_{0}\right)$ and sill $\left.\left(C+C_{0}\right)\right)$ were obtained. In this study, ordinary kriging was used to interpolate concentration values and create the spatial distribution maps of As and metals. For the assessment of contamination risks, the disjunctive kriging technique was used to estimate the probability that the true values of concentrations of As and metals at unsampled points exceed the specified thresholds. The disjunctive kriging is based on the assumption that our data are a realization of a process with a second-order stationary bivariate distribution. This method was described in more detail by Rivoirard (1994) and Matheron (1962). This method can be used to estimate the original soil variable, and the conditional probability for specified thresholds. The experimental semivariogram functions were computed and modeled by using the software package GS+ (Gamma Design, 1994), while kriging estimation and spatial distribution maps of As and metals were obtained by using the geostatistical analyst extension of ArcGIS 9.2 ${ }^{\circledR}$ for Windows.

\section{Results and discussion}

\subsection{Descriptive statistics of concentrations of As and metals in soils around Miyun Reservoir}

Summary descriptive statistics of the concentrations of $\mathrm{Cr}, \mathrm{Ni}$, $\mathrm{Cu}, \mathrm{Zn}, \mathrm{Cd}, \mathrm{As}$ and $\mathrm{Pb}$ are provided (Table 1 ). The application of the
$\mathrm{K}-\mathrm{S}$ test confirmed that the concentrations of As and metals in the soils were not normally distributed but the $\log _{10}$-transformation resulted in a distribution that approximated a normal distribution ( $\mathrm{K}-\mathrm{S} p>0.05)$. Therefore, the geometric means (geomean) of As and metals were compared with background concentrations in soils of Beijing (Chen et al., 2004). The geomean of $\mathrm{Cr}$ (37 $\mathrm{mg} \mathrm{kg}^{-1} \mathrm{dw}$ ) was significantly greater than the background concentration ( $31 \mathrm{mg} \mathrm{kg}^{-1} \mathrm{dw}$ ) (one-sample test, $P<0.05$ ). The geomeans of As and the other metals were generally similar to or less than Beijing background concentrations. The number of samples exceeding the corresponding background concentration for $\mathrm{Cr}, \mathrm{Cu}, \mathrm{Zn}$, As and $\mathrm{Ni}$ was 56, 40, 37, 10 and 6, respectively. Multiplying the ratios of the geomeans to the corresponding background concentrations by the number of values exceeding the respective background concentration provides a combined estimate of both the magnitude and the extent of contamination around the reservoir. This weighted result suggests that the magnitude of exceeding the background concentrations of As and metals in soils around Miyun Reservoir is in the descending order of $\mathrm{Cr}>\mathrm{Cu}>\mathrm{Zn}>\mathrm{As}>\mathrm{Ni}$. All the concentrations of $\mathrm{Cd}$ and $\mathrm{Pb}$ were less than their respective background concentrations, indicating no apparent anthropogenic contamination with $\mathrm{Cd}$ and $\mathrm{Pb}$. The variations in concentrations of $\mathrm{Cr}, \mathrm{Cu}$ and $\mathrm{Zn}$ were indicative of heterogeneous sources and likely due to human activities. It has been reported that mining activities (such as iron, chromite and gold mines) have existed in Miyun County where the iron ore deposit is very rich (about $9 \times 10^{9}$ tons, accounting for $98 \%$ of its total deposit in Beijing) (Gao and Liao, 2007). The main component of iron mine tailings in this area was ferrous chromite $\left(\mathrm{FeCr}_{2} \mathrm{O}_{4}\right)$ 
Table 1

Summary statistics of arsenic and metal concentrations in surface soil (from measurements in $\mathrm{mg} \mathrm{kg}^{-1} \mathrm{dw}$ ).

\begin{tabular}{|c|c|c|c|c|c|c|c|}
\hline & $\mathrm{Cr}$ & $\mathrm{Ni}$ & $\mathrm{Cu}$ & $\mathrm{Zn}$ & $\mathrm{Cd}$ & As & $\mathrm{Pb}$ \\
\hline Sample number & 95 & 95 & 95 & 95 & 95 & 95 & 95 \\
\hline Arithmetic mean & 40 & 18 & 23 & 64 & 0.05 & 6.5 & 11 \\
\hline Geometric mean & 37 & 17 & 19 & 55 & 0.049 & 5.5 & 9.9 \\
\hline Median & 33 & 16 & 18 & 55 & 0.050 & 6.7 & 10 \\
\hline Standard deviation & 20 & 8.3 & 20 & 18 & 0.022 & 2.1 & 0.6 \\
\hline Minimum & 15 & 4.9 & 5.5 & 12 & 0.023 & 3.5 & 5.0 \\
\hline Maximum & $1.3 \times 10^{2}$ & 58 & 68 & $1.0 \times 10^{2}$ & 0.055 & 11 & 24 \\
\hline Skewness & 1.9 & 2.3 & 2.0 & 0.39 & -4.9 & 0.60 & 1.6 \\
\hline Kurtosis & 5.0 & 9 & 5.9 & 1.3 & 35 & 2.7 & 4.2 \\
\hline $\mathrm{K}-\mathrm{S} p$ & 0.040 & 0.13 & 0.035 & 0.75 & 0 & 0.25 & 0.21 \\
\hline $\begin{array}{l}\text { Beijing background } \\
\text { concentration }\end{array}$ & $31^{a}$ & $28^{a}$ & $20^{\mathrm{a}}$ & $60^{a}$ & $0.15^{\mathrm{a}}$ & $7.8^{\mathrm{a}}$ & $25^{\mathrm{a}}$ \\
\hline $\begin{array}{l}\text { Number exceeding } \\
\text { background } \\
\text { concentration } \\
\text { of Beijing }\end{array}$ & 56 & 6 & 40 & 37 & 0 & 10 & 0 \\
\hline \multicolumn{8}{|l|}{ Log-transformation } \\
\hline Skewness & 0.87 & -0.12 & 0.20 & -1.5 & -6.5 & -0.61 & 0.20 \\
\hline Kurtosis & 0.99 & 2.0 & 0.10 & 7.9 & 49 & 2.4 & 0.9 \\
\hline $\mathrm{K}-\mathrm{S} p$ & 0.14 & 0.21 & 0.68 & 0.79 & 0 & 0.22 & 0.52 \\
\hline
\end{tabular}

a Chen et al. (2004).

(Westbrook, 1983; Gao and Liao, 2007). On the other hand, anthropogenic inputs of $\mathrm{Cr}$ in fertilizers, limestone and manure are, generally, less than concentrations already present in soils (Facchinelli et al., 2001). Consequently, long-term mining of iron ores is the most likely cause of elevated $\mathrm{Cr}$ contamination in soils (Marmolejo-Rodríguez et al., 2007). In fact greater concentrations of $\mathrm{Cr}$ were observed in the vicinities of the iron ore mine (Marmolejo-Rodríguez et al., 2007). Fertilizer and pesticides are considered as important sources of $\mathrm{Zn}$ and $\mathrm{Cu}$ in the environment (Xue et al., 2000; Nicholson et al., 2003). Thus, it can be hypothesized that the source for $\mathrm{Zn}$ and $\mathrm{Cu}$ in the soils are from application of fertilizer and pesticides in agriculture. The small and fairly consistent concentrations of $\mathrm{Cd}$ and $\mathrm{Pb}$ are consistent with minor anthropogenic input of these metals to soils of this region. It was reported that concentrations of these metals near iron ore mines were small (Marmolejo-Rodríguez et al., 2007).

\subsection{Statistical analysis}

In order to establish inter-element relationships in soil samples, correlation coefficients for As and metals were calculated (Table 2). The significant positive correlation between $\mathrm{Cd}, \mathrm{Cu}, \mathrm{Zn}$ and $\mathrm{Ni}$ is consistent with a common source for these metals. Associations among these metals can be indicative of sources due to human activities or geogenic and pedogenic characteristics (Facchinelli et al., 2001; Rodríguez Martín et al., 2008). As and Pb were significantly negative correlated to $\mathrm{Cd}, \mathrm{Cu}, \mathrm{Zn}$ and $\mathrm{Ni}$. Therefore, As and $\mathrm{Pb}$ have different sources from those of $\mathrm{Cd}, \mathrm{Cu}, \mathrm{Zn}$ and Ni. Significant positive correlation (0.68) was found between $\mathrm{Cr}$ and $\mathrm{Ni}$ and thus, it seems likely that they are from the same source. Since As was not correlated to $\mathrm{Pb}$, As had no the same source with $\mathrm{Pb}$.

Principal component analysis was conducted to ascertain possible contributing factors towards the concentrations of As and metals and thereby determine which elements have a common origin. By extracting the eigenvalues and eigenvectors from the correlation matrix, the number of significant factors, the proportion of variance explained by each of them and rotated component matrix are given (Table 3). Only three eigenvalues were found to be $>1$ and explained approximately $90 \%$ of the variance. The first three eigenvalues were therefore selected for further analysis, while
Table 2

Pearson correlation matrix for arsenic and metal concentrations.

\begin{tabular}{cccccccc}
\hline & $\mathrm{Cr}$ & $\mathrm{Ni}$ & $\mathrm{Cu}$ & $\mathrm{Zn}$ & $\mathrm{Cd}$ & $\mathrm{As}$ & $\mathrm{Pb}$ \\
\hline $\mathrm{Cr}$ & 1 & & & & & & \\
$\mathrm{Ni}$ & $0.68^{* *}$ & 1 & & & & & \\
$\mathrm{Cu}$ & 0.2 & $0.76^{* *}$ & 1 & & & & \\
$\mathrm{Zn}$ & -0.17 & $0.53^{* *}$ & $0.86^{* *}$ & 1 & & & \\
$\mathrm{Cd}$ & $-0.27^{*}$ & $0.41^{* *}$ & $0.68^{* *}$ & $0.88^{* *}$ & 1 & & \\
$\mathrm{As}$ & -0.02 & $-0.32^{* *}$ & $-0.47^{* *}$ & $-0.53^{* *}$ & $-0.4^{* *}$ & 1 & \\
$\mathrm{~Pb}$ & -0.11 & $-0.32^{* *}$ & $-0.27^{*}$ & $-0.26^{*}$ & $-0.41^{* *}$ & -0.16 & 1 \\
\hline
\end{tabular}

*correlation is significant at the 0.05 level (two-tailed); ${ }^{* *}$ Correlation is significant at the 0.01 level (two-tailed).

other small but non-zero eigenvalues were discarded for the purpose of establishing a probable number of contributing source factors. The initial eigenvalues extracted were "cleaned up" by means of Varimax rotation. It is evident from the rotated component matrix that As and metals are explained by three factors. The first factor spanning the greater amount of variance (50.33\%) includes $\mathrm{Cu}, \mathrm{Zn}, \mathrm{Cd}$ and $\mathrm{Ni}$. This factor (source) is likely due to both human activities and natural influences. Apparently, anthropogenic influences to these metals include application of fertilizer and pesticides in agriculture. Soil parent materials are the natural factors that account for lesser concentrations of these metals than their background concentrations. Both $\mathrm{Cr}$ and $\mathrm{Ni}$ appear in the second factor, which is likely due to anthropogenic influences. The significant human activities that affect concentrations of elements in soils are primarily iron ore mining activities (Xue et al., 2000; Wang and Wang, 2005) which are responsible for greater concentrations of $\mathrm{Cr}$ and $\mathrm{Ni}$ than their background concentrations around Miyun Reservoir. $\mathrm{Pb}$ concentrations are less than the background concentrations, which represent the source of parent rocks. It seems that arsenic is included in neither the second factor nor the first or the third factor. Furthermore, considering 10 samples having As concentrations greater than its background level and the correlations between As and metals, it could be deduced that greater concentrations of As than its background level could be caused by sources different from iron mining and agricultural chemical input.

\subsection{Spatial analysis}

\subsubsection{Geostatistical analysis}

Geostatistics provides an advanced methodology which facilitates quantification of the spatial features of soil parameters and enables spatial interpolation (Zhang and Selinus, 1998; Hengl et al., 2009; Carlon et al., 2001). It has become a useful tool for the study of spatial uncertainty and hazard assessment (Goovaerts, 2001). Semivariogram models and best-fit model parameters are given (Table 3), while diagrams are plotted (Fig. 2). These models were chosen based on regression coefficient of determination $\left(R^{2}\right)$ and residual sums of squares (RSS) provided by GS+ software. Spherical, exponential and Gaussian models were chosen as appropriate for all direct semivariograms after visual inspection of sample semivariograms and a cross-validation check. In all cases the models were assumed to be isotropic. Therefore, kriging was performed assuming a circular search radius, with a range equal to the semivariogram range, and a maximum number of 10 neighbors. The optimal theoretical models of $\mathrm{Cu}$ and $\mathrm{Zn}$ were spherical models. $\mathrm{Cr}$ was best fit to an exponential model. $\mathrm{Cd}, \mathrm{Ni}, \mathrm{Pb}$ and As were best fit to gaussian models. The existence of a positive nugget effect in some of the variables studied can be explained by sampling error, short-range variability, and unexplained and inherent variability (McGrath et al., 2004). It is shown (Table 4) that all semivariograms 
Table 3

Total variance explained and component matrixes. ${ }^{a}$

\begin{tabular}{|c|c|c|c|c|c|c|c|c|c|}
\hline \multicolumn{10}{|c|}{ Total variance explained } \\
\hline \multirow[t]{2}{*}{ Component } & \multicolumn{3}{|c|}{ Initial Eigenvalues } & \multicolumn{3}{|c|}{ Extraction sums of squared loadings } & \multicolumn{3}{|c|}{ Rotation sums of squared loadings } \\
\hline & Total & $\%$ of Variance & Cumulative \% & Total & $\%$ of Variance & Cumulative \% & Total & $\%$ of Variance & Cumulative \% \\
\hline 1 & 3.52 & 50.33 & 50.33 & 3.52 & 50.33 & 50.33 & 3.29 & 47.01 & 47.01 \\
\hline 2 & 1.63 & 23.25 & 73.58 & 1.63 & 23.25 & 73.58 & 1.82 & 25.96 & 72.97 \\
\hline 3 & 1.17 & 16.68 & 90.26 & 1.17 & 16.68 & 90.26 & 1.21 & 17.29 & 90.26 \\
\hline 4 & 0.43 & 6.09 & 96.35 & & & & & & \\
\hline 5 & 0.17 & 2.37 & 98.72 & & & & & & \\
\hline 6 & 0.05 & 0.67 & 99.40 & & & & & & \\
\hline 7 & 0.04 & 0.60 & 100.00 & & & & & & \\
\hline \multicolumn{10}{|c|}{ Component matrixes } \\
\hline \multirow[t]{2}{*}{ Element } & & \multicolumn{4}{|c|}{ Component matrix } & \multicolumn{4}{|c|}{ Rotated component matrix } \\
\hline & & PC1 & PC2 & & PC3 & PC1 & & PC2 & PC3 \\
\hline $\mathrm{Cr}$ & & 0.15 & 0.96 & & 0.15 & -0.18 & & 0.97 & 0.02 \\
\hline $\mathrm{Ni}$ & & 0.77 & 0.60 & & 0.05 & 0.52 & & 0.82 & 0.13 \\
\hline $\mathrm{Cu}$ & & 0.93 & 0.07 & & 0.08 & 0.85 & & 0.39 & 0.05 \\
\hline $\mathrm{Zn}$ & & 0.92 & -0.32 & & 0.01 & 0.97 & & 0.00 & 0.05 \\
\hline $\mathrm{Cd}$ & & 0.84 & -0.41 & & -0.22 & 0.91 & & -0.14 & 0.25 \\
\hline As & & -0.57 & 0.19 & & -0.64 & -0.64 & & -0.12 & 0.59 \\
\hline $\mathrm{Pb}$ & & -0.40 & -0.17 & & 0.82 & -0.26 & & -0.14 & -0.88 \\
\hline
\end{tabular}

${ }^{\text {a }}$ Extraction method: principal component analysis. rotated method: varimax with Kaiser normalization.

are generally well structured with small nugget effect, showing that the sampling density is adequate to reveal the spatial structures.

The range is considered as the distance beyond which observations are not spatially dependent (Gallardo, 2003). Comparing the range of As and metals, it was found that $\mathrm{Cd}$ and $\mathrm{Pb}$ have longer effective ranges than As and the other metals, which indicates that $\mathrm{Cd}$ and $\mathrm{Pb}$ have better spatial structure and less variation caused by extrinsic factors. Human activities have effects on only short and medium-range scales of variation (Rodríguez Martín et al., 2008). In this study, semivariograms of $\mathrm{Cr}, \mathrm{Cu}$ and $\mathrm{Zn}$ are dominated by short-range structure, and the semivariogram of As and $\mathrm{Ni}$ are of medium-range variation. This result suggests that human activities affect the spatial distribution of $\mathrm{Cr}, \mathrm{Cu}$ and $\mathrm{Zn}$ while the spatial distribution of the As and $\mathrm{Ni}$ are equally controlled by both geological process and human activities.

\subsubsection{Spatial distribution and risk assessment}

The variogram models were used as input for ordinary kriging and the resulting contour maps are shown (Fig. 3). The general trend was that concentrations of $\mathrm{Cr}$ were greater around the reservoir in Miyun County and in most of Xinglong County. The greater concentrations of $\mathrm{Cr}$ in these areas are presumably of anthropogenic origin on a local scale. It has been reported that most iron ores are found to the east of the reservoir, especially in the delta of the Chaohe River. Contamination of soils by $\mathrm{Cu}$ was only observed in patches located to the east of the reservoir where ore mining activities and large-scale animal feeding has taken place (Gao and Liao, 2007). Coincidentally, orchard land in which $\mathrm{Cu}$ fungicides were repeatedly used (Loland and Singh, 2004) are mainly distributed to the east of the reservoir. Thus, applications of metal-containing fungicides in orchards can result in increased $\mathrm{Cu}$ content in soils. Greater Zn contamination was observed in the east of Xinglong County and the south of Chengde County. These places are remote from Miyun Reservoir. However, there is still a patch in which the concentrations of $\mathrm{Zn}$ can be greater than its background concentration $\left(60 \mathrm{mg} \mathrm{kg}^{-1} \mathrm{dw}\right)$. This area is close to and in the northwest of the reservoir where three rivers (namely Tanghe, Heihe and Baihe Rivers) converge and enter the reservoir. Animal feeding and fertilizer application are focused in this area, causing high levels of $\mathrm{Zn}$ in the soils. The maximum concentrations of $\mathrm{Ni}$ were distributed in the east of Miyun Reservoir in Miyun County where the mining activities occurred. A good correlation between concentrations of $\mathrm{Ni}$ and $\mathrm{Cr}$ (Table 2) was consistent with mining activities being the source of enrichment of $\mathrm{Ni}$ in the study area. The greater concentrations of As were found upstream in the Baihe River in Chicheng County where small-scale gold mining activities existed. It has been reported that As was a concomitant in gold ore (Liu et al., 2005). This might be the reason for the greater concentrations of As at upstream regions of the Baihe River. Although the area of greater concentrations of As was remote from the west of Miyun Reservoir, its potential impact on water in Miyun Reservoir is still possible.

Mean and maximum concentrations of $\mathrm{Cd}$ and $\mathrm{Pb}$ (Table 1 ) were considered small relative to corresponding background concentrations (Chen et al., 2004). Thus, these two metals are unlikely to constitute a risk for environmental pollution or threat to human health. Compared with background concentrations (Table 1) the probabilities of $\mathrm{Cr}, \mathrm{Cu}, \mathrm{Zn}$, As and Ni were estimated. The risk patches resulted from disjunctive kriging were given (Fig. 4). The probability of concentrations of $\mathrm{Cr}$ in soils to the east of Miyun Reservoir including Xinglong, part of Miyun and Chengde Counties exceeding the background concentration was $0.75-0.97$ (Fig. 4 ). For soil $\mathrm{Cu}$, the probability of $\mathrm{Cu}$ exceeding $20 \mathrm{mg} \mathrm{kg}^{-1}$ exhibited a small patch of greater contamination risk with estimated probability $(0.69-0.83)$ to the east of the reservoir in Miyun County. The probability of $\mathrm{Zn}$ exceeding $60 \mathrm{mg} \mathrm{kg}^{-1}$ was estimated to be $0.5-0.75$ at the areas far from the reservoir. However, the probability of As exceeding $7.8 \mathrm{mg} \mathrm{kg}^{-1}$ was estimated to be $0.29-0.33$ in the upstream region of the Baihe River. For soil Ni, the probability of exceeding $28 \mathrm{mg} \mathrm{kg}^{-1}$ indicated a small patch of contamination risk with estimated probability (0.29-0.39) to the east of the reservoir in Miyun County.

If the water quality of the Miyun Reservoir is to be protected, concentrations of $\mathrm{Cr}, \mathrm{Zn}, \mathrm{Cu}, \mathrm{As}$ and $\mathrm{Ni}$ which already exceed background concentrations or where the probabilities of their exceeding those values are substantial should not be allowed to increase further. Control will be needed to reduce risk from these metals in the soils. Maps of As and metal concentration and conditional probability provide the information for that purpose. The data also provided a scientific basis for best-management practices for Miyun Reservoir watershed. 

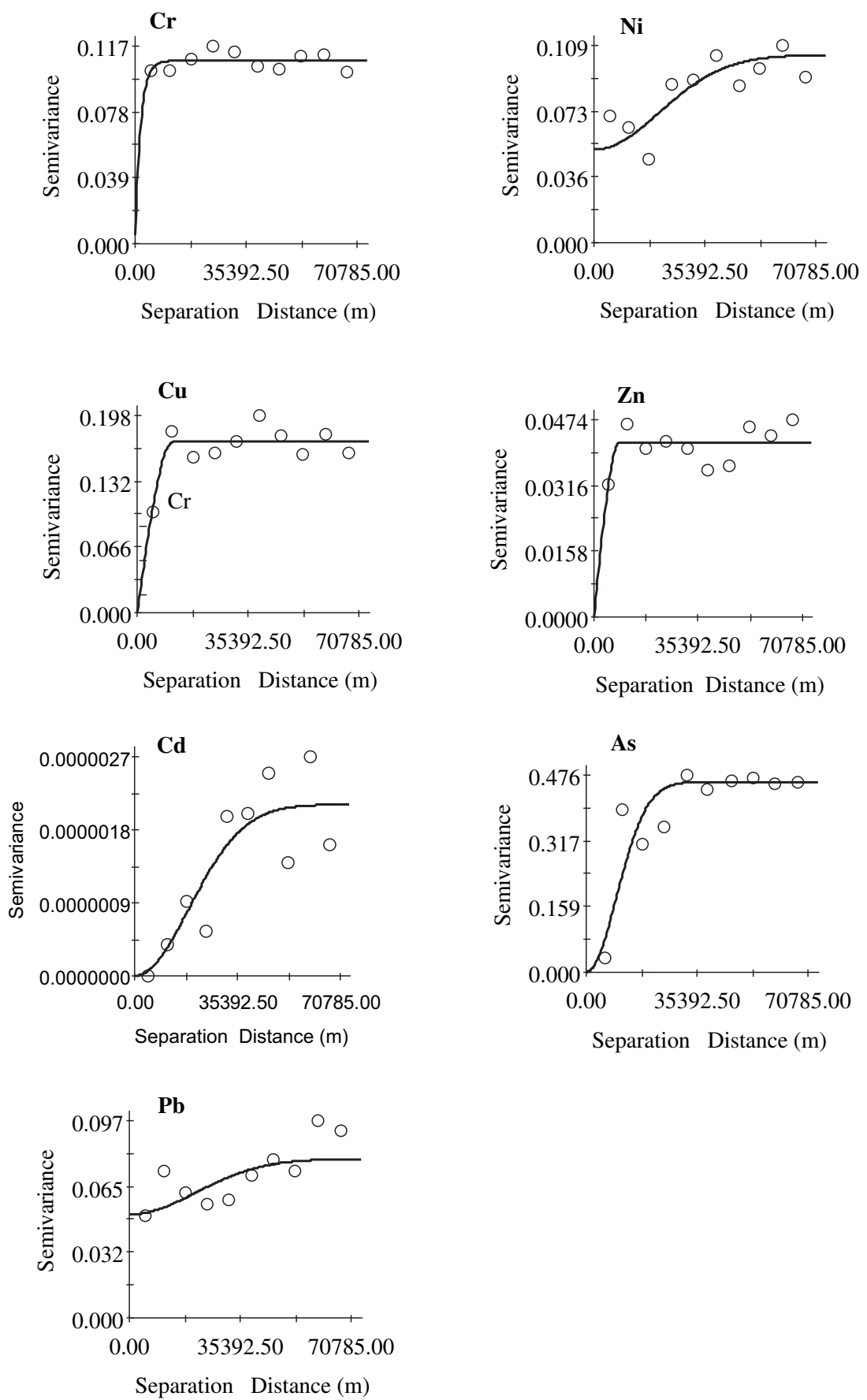

Fig. 2. Experimental semivariograms of arsenic and metals in soils with fitted models.

Table 4

Best-fitted semivariogram models of arsenic and metals and their parameters.

\begin{tabular}{|c|c|c|c|c|c|c|c|}
\hline Metals & Transformed & Model & $C_{0}$ & $C+C_{0}$ & Range (km) & $R^{2}$ & RSS \\
\hline $\mathrm{Cr}$ & $\log$ & Exponential & 0.0048 & 0.11 & 5.4 & 0.81 & $2.4 \times 10^{-4}$ \\
\hline $\mathrm{Ni}$ & Log & Gaussian & 0.050 & 0.10 & 29.5 & 0.65 & $1.3 \times 10^{-3}$ \\
\hline $\mathrm{Cu}$ & Log & Spherical & 0.0002 & 0.17 & 11.4 & 0.74 & $1.6 \times 10^{-3}$ \\
\hline $\mathrm{Zn}$ & $\log$ & Spherical & 0.0001 & 0.042 & 12.7 & 0.61 & $1.6 \times 10^{-4}$ \\
\hline $\mathrm{Cd}$ & Log & Gaussian & 0 & $2 \times 10^{-6}$ & 46 & 0.75 & $1.9 \times 10^{-12}$ \\
\hline As & Log & Gaussian & $1 \times 10^{-3}$ & 0.46 & 24 & 0.78 & 0.045 \\
\hline $\mathrm{Pb}$ & Log & Gaussian & 0.05 & 0.079 & 52 & 0.66 & $1.1 \times 10^{-3}$ \\
\hline
\end{tabular}

$C_{0}$, nugget variance; $C+C_{0}$, sill variance; $R^{2}$, regression coefficient of determination; RSS, residual sums of squares. 

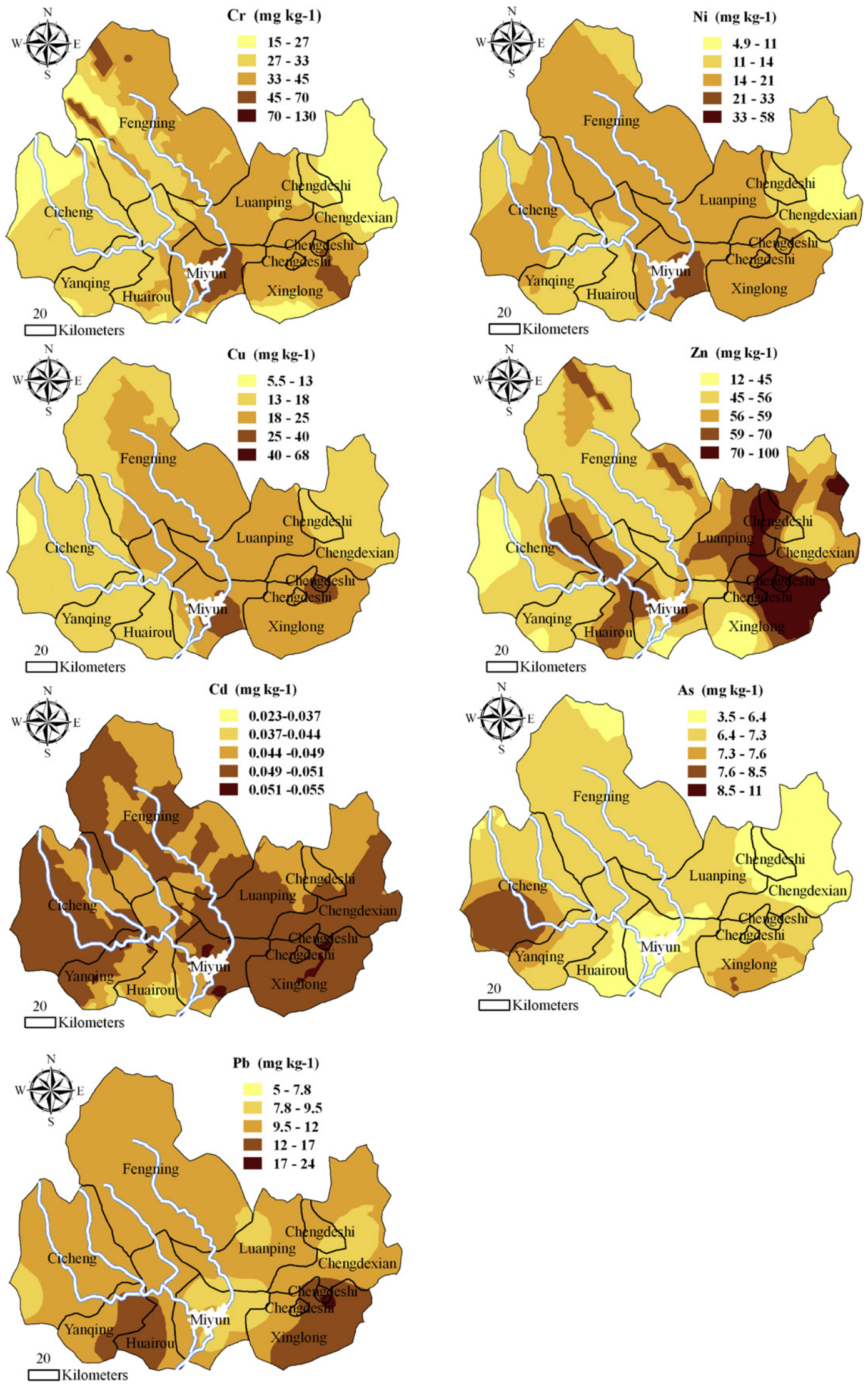

Fig. 3. Contour maps for arsenic and metal concentrations in the soils around Miyun Reservoir. 

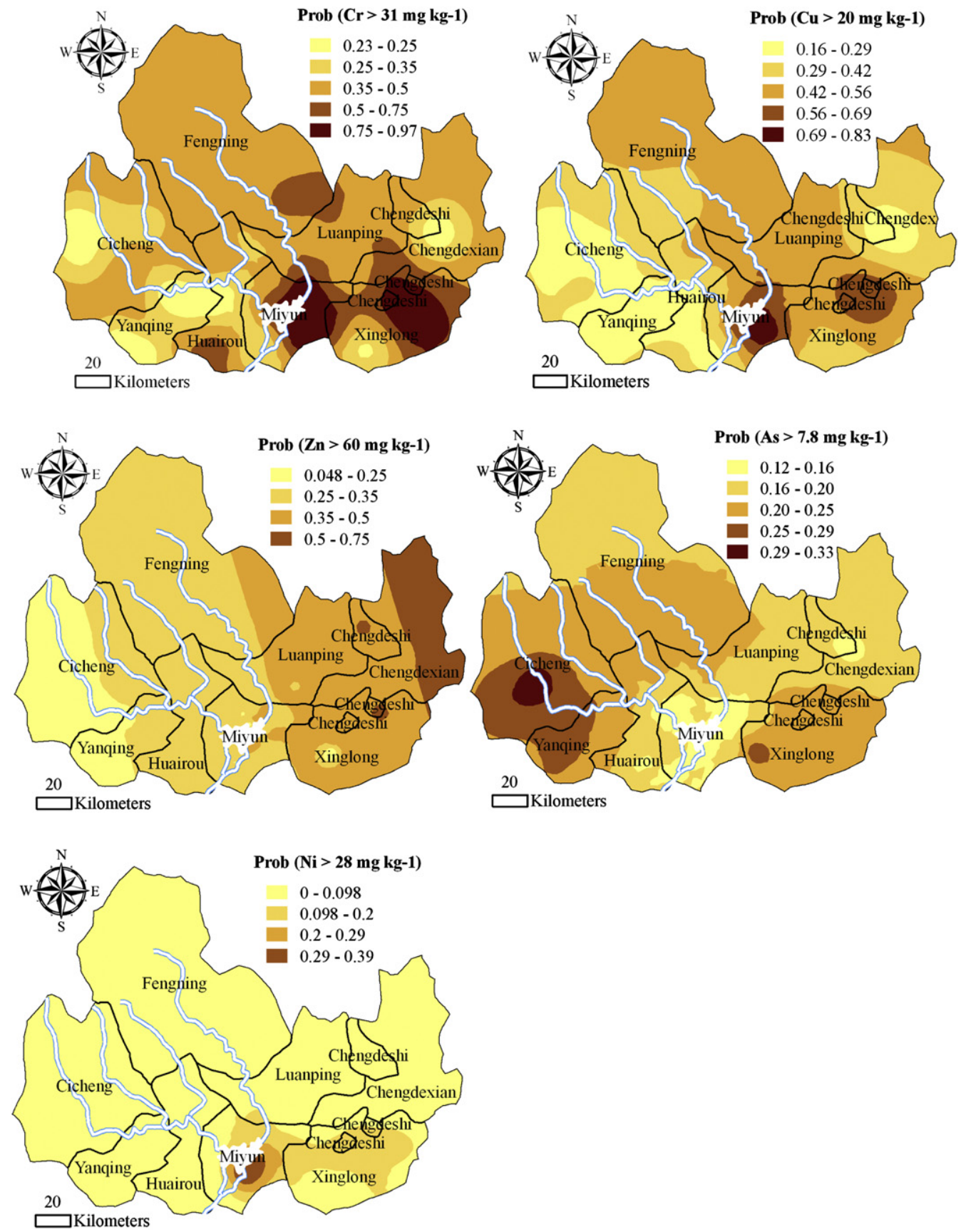

Fig. 4. The estimated probability maps of $\mathrm{Cr}, \mathrm{Cu}, \mathrm{Zn}$, As and $\mathrm{Ni}$ being greater than the background values.

\section{Conclusions}

Mining activities (especially iron ore) in the northeast areas of the Miyun Reservoir have caused serious $\mathrm{Cr}$ contamination and the elevated concentrations of $\mathrm{Ni}$ in the soils. $\mathrm{Cd}, \mathrm{Cu}, \mathrm{Zn}$ and $\mathrm{Ni}$ are inter-correlated, originating from natural processes and human influences. Using fertilizers, pesticides and fungicides related to agricultural practices in the study area has increased the concentrations of $\mathrm{Zn}$ and $\mathrm{Cu}$ in the soils. The greater concentrations of As occurred at upstream portions of the Baihe River in Chicheng County. To reduce its risk, some measures should been taken to reduce the release of As from small scale gold mining activities in Chicheng County. Currently concentrations of $\mathrm{Pb}$ and $\mathrm{Cd}$ in soils do not present a risk.
Transport of As and metals from mining activities is representative of a class of water quality problems. Unmanaged metals such as $\mathrm{Cr}, \mathrm{Cu}, \mathrm{Zn}$, As and Ni released from upland sources, their transport across the land surface, and delivery to watershed systems can have adverse water quality and ecological impacts upon the reservoir to a considerable extent. Thus, the Beijing government should forbid any mining activities (especially iron and gold ore mining) and limit the agricultural chemical input to the Miyun Reservoir watershed.

\section{Acknowledgements}

This research was supported by the National Basic Research Programs with grant Nos. 2008CB418104 and 2007CB407307, 
National Natural Science Foundation of China with grant No. 30840026, the Knowledge Innovation Programs of the Chinese Academy of Sciences (CAS) with grant Nos. KZCX2-YW-420-5 and KZCX1-YW-06-05-02, Einstein Professorship Program, CAS, and the Project of State Key Lab of Urban and Regional Ecology with grant No. SKLURE2008-1-04. Prof. Giesy was supported by the Canada Research Chair program.

\section{References}

Bonten, L.T.C., Römkens, P.F.A.M., Brus, D.J., 2006. Leaching of heavy metals from agricultural soils: an important source of surface water contamination. 10th Conference on Diffuse Pollution, Istanbul, Turkey.

Carlon, C., Critto, A., Marcomini, A., Nathanail, P., 2001. Risk based characterisation of contaminated industrial site using multivariate and geostatistical tools. Environmental Pollution 111, 417-427.

Chen, T.B., Zheng, Y.M., Chen, H., Zheng, G.D., 2004. Background concentrations of soil heavy metals in Beijing. Environmental Science 25, 117-122 (in Chinese).

Facchinelli, A., Sacchi, E., Mallen, L., 2001. Multivariate statistical and GIS-based approach to identify heavy metal sources in soils. Environmental Pollution 114, 313-324.

Gallardo, A., 2003. Spatial variability of soil properties in a floodplain forest in northwest Spain. Ecosystems 6, 564-576.

Gamma Design, 1994. Geostatistics For The Environmental Sciences, Version 2.3. Gamma Design, Plainwell, MI.

Gao, Z.D., Liao, H.J., 2007. Investigation and assessment on pollution of soil heavy metals in up-stream of Miyun Reservoir. China Environmental Protection Industry 8, 23-26 (in Chinese).

García, J.H., Li, W.W., Arimoto, R., Okrasinski, R., Greenlee, J., Walton, J., 2004 Characterization and implication of potential fugitive dust sources in the Paso del Norte region. Science of the Total Environment 325, 95-112.

Ge, X., Liu, X., Pan, X., Li, Q., Luo, S., 2003. The geochemical characteristics of water body in Miyun Reservoir. Rock and Mineral Analysis 22, 44-48 (in Chinese).

Gong, Z., Zhang, G., Chen, Z., Luo, G., Zhao, W., 2002. Soil reference on the bases of Chinese soil taxonomy. Chinese Journal of Soil Science 33,1-5 (in Chinese).

Goovaerts, P., 2001. Geostatistical modeling of uncertainty in soil science. Geoderma $103,3-26$.

Hengl, T., Minasny, B., Gould, M., 2009. A geostatistical analysis of geostatistics. Scientometrics 80, 491-514.

Kaiser, H.F., 1960. The application of electronic computers to factor analysis. Educational and Psychological Measurement 20, 141-151.

Li, X., Lee, S.-L., Wong S.-C., Shi, W., Thornton, I., 2004. The study of metal contamination in urban soils of Hong Kong using a GIS-based approach. Environmental Pollution 129, 113-124.

Liu, X., Xu, Q., Ge, X., Liu, L., Wu, D., 2005. Speciation analysis of metals in the sediments of Miyun Reservoir. Science in China, Ser D Earth Science 35 (Suppl.), 288-295.

Loland, J.Ø., Singh, B.R., 2004. Copper contamination of soil and vegetation in coffee orchards after long-term use of $\mathrm{Cu}$ fungicides. Nutrient Cycling in Agroecosystems 69, 203-211.

Luo, W., Wang, T.Y., Lu, Y.L., Giesy, J.P., Shi, Y.J., Zheng, Y.M., Xing, Y., Wu, G., 2007. Landscape ecology of the Guanting Reservoir, Beijing, China: multivariate and geostatistical analyses of metals in soils. Environmental Pollution 146, 567-576.
Marmolejo-Rodríguez, A.J., Prego, R., Meyer-Willerer, A., Shumilin, E., CobeloGarcí, A., 2007. Total and labile metals in surface sediments of the tropical riverestuary system of Marabasco (Pacific coast of Mexico): influence of an iron mine. Marine Pollution Bulletin 55, 459-468.

Matheron, G., 1962. Traité de Géostatistique Appliqué, Tome 1. Memoires du Bureau de Recherches Géologiques et Minières, Paris, France. Editions Technip, Paris.

McGrath, D., Zhang, C.S., Carton, O.T., 2004. Geostatistical analyses and hazard assessment on soil lead in Silvermines area, Ireland. Environmental Pollution 127, 239-248.

Nicholson, F.A., Smith, S.R., Alloway, B.J., Carlton-Simith, C., Chambers, B.J., 2003. An inventory of heavy metal input to agricultural soil in England and Wales. Science of the Total Environment 311, 205-219.

Rivoirard, J., 1994. Introduction to Disjunctive Kriging and Non-Linear Geostatistics. Oxford University Press, Oxford, UK.

Rodríguez Lado, L., Hengl, T., Reuter, H., 2008. Heavy metals in European soils: a geostatistical analysis of the FOREGS Geochemical database. Geoderma 148, 189-199.

Rodríguez Martín, J.A., Nanos, N.J.M., Gil, L., López Arias, M., 2008. Multiscale analysis of heavy metal contents in Spanish agricultural topsoils. Chemosphere 70, 1085-1096.

Schipper, P.N.M., Bonten, L.T.C., Plette, A.C.C., Moolenaar, S.W., 2008. Measures to diminish leaching of heavy metals to surface waters from agricultural soils. Desalination 226, 89-96.

State Environmental Protection Administration of China, 2004. The Technical Specification for Soil Environmental Monitoring (HJ/T 166-2004). The Industrial Standard of The People's Republic of China Environmental Protection, Beijing (in Chinese) $1-44$.

Tao, S., 1995. Kriging and mapping of copper, lead and mercury contents in surface soil in Shenzhen area. Water, Air and Soil Pollution 83, 161-172.

USEPA, 1996. In: Test Methods for Evaluating Solid Waste, SW 846, third ed. Office of Solid Waste and Emergency Response, Washington, DC.

Wang, X., Guo, F., Cai, X., Hu, Q., 2003. Non-point source pollution loading of Miyun Reservoir, Beijing. Urban Environment and Urban Ecology 16, 31-33 (in Chinese).

Wang, X., Wang, Q., 2005. Livestock manure load of farmland in Miyun County and its environmental risk assessment. Rural Eco-Environment 21, 30-34 (in Chinese).

Webster, R., Oliver, M.A., 2001. Geostatistics for Environmental Scientists. John Wiley \& Sons Ltd, Chichester.

Westbrook, J., 1983. Chromium and chromium alloys. In: Grayson, M. (Ed.), KirkOthmer Encyclopedia of Chemical Technology. Wiley-Interscience, New York, pp. 54-82.

Xue, H.B., Sigg, L., Gächter, R., 2000. Transport of $\mathrm{Cu}, \mathrm{Zn}$ and $\mathrm{Cd}$ in a small agricultural catchment. Water Research 34, 2558-2568.

Zhang, C., Selinus, O., 1998. Statistics and GIS in environmental geochemistry some problems and solutions. Journal of Geochemical Exploration 64, 339-354.

Zhang, Q., Shi, X., Huang, B., Yu, D., Oborn, I., Blomback, K., Wang, H., Pagella, T.F. Sinclair, F.L., 2007. Surface water quality of factory-based and vegetablebased peri-urban areas in the Yangtze River Delta region, China. Catena 69, 57-64.

Zhuang, M., Jia, H., Wang, W., Ding, Z., 2005. Study on existent form of mercury in sediment s of Miyun Reservoir, Beijng. Environmental Protection Science 31, 23-25 (in Chinese) 